Article

\title{
Common Grounded H-Type Bidirectional DC-DC Converter with a Wide Voltage Conversion Ratio for a Hybrid Energy Storage System
}

\author{
Huakun Bi, Ping Wang * (D) and Zhishuang Wang \\ School of Electrical and Information Engineering, Tianjin University, Tianjin 300072, China; \\ bihuakun@163.com (H.B.); ezswang@163.com (Z.W.) \\ * Correspondence: pingw@tju.edu.cn
}

Received: 2 January 2018; Accepted: 23 January 2018; Published: 2 February 2018

\begin{abstract}
Hybrid energy storage systems (HESS) play an important role in maintaining the power balance of a direct current (DC) micro-grid. A HESS is mainly composed of high power density super-capacitors (SCs) and high energy density batteries. According to the operational requirements of an SC, a bidirectional DC-DC converter with the characteristics of a good dynamic response and a wide voltage conversion ratio is needed to interface the SC and a high-voltage DC bus. In this paper, a novel common grounded $\mathrm{H}$-type bidirectional converter characterized by a good dynamic response, a low inductor current ripple, and a wide voltage conversion ratio is proposed. In addition, it can avoid the narrow pulse of pulse width modulation (PWM) voltage waveforms when a high voltage conversion ratio is achieved. All of these features are beneficial to the operation of the SC connected to a DC bus. The operating principle and characteristics of the proposed converter are presented in this paper. A $320 \mathrm{~W}$ prototype with a wide voltage conversion ranging from 3.3 to 8 in step-up mode and $1 / 8$ to $1 / 3$ in step-down mode has been constructed to validate the feasibility and effectiveness of the proposed converter.
\end{abstract}

Keywords: H-type bidirectional DC-DC converter; good dynamic response; hybrid energy storage system; wide voltage conversion ratio

\section{Introduction}

With the high penetration of direct current (DC) energy sources, storage, and loads, DC micro-grids are becoming more prevalent due to a lower number of power converters compared with an alternating current (AC) micro-grid [1-3]. Because of the intermittent nature of renewable energy sources and unpredictable load fluctuations in DC micro-grids, the problem of power imbalance may appear and affect the operation of DC micro-grids. Therefore, energy storage systems (ESs) are always installed to maintain the power balance of the DC micro-grid [4,5]. ESs can be divided into a power density type and an energy density type based on their characteristics [6,7]. Unfortunately, there is no single type of ES that fulfills all expected features [8]. Therefore, it is an economic and effective solution to use a hybrid energy storage system (HESS) composed by different characteristics of ESs [9-11]. Generally, a HESS is mainly composed of high power density super-capacitors (SCs) and high energy density batteries. It is desirable to balance the steady-state power imbalance by the batteries and compensate for the transient power imbalance by an SC with fast dynamics [12-14]. As a result, the degradation impact on the batteries caused by sudden load changes can be greatly reduced, and the dynamic response of the whole DC micro-grid can also be improved $[15,16]$.

As mentioned above, high power density SCs play an important role in a HESS. However, the output voltage of an SC is relatively low and changes widely. In order to connect the SC to a high voltage level DC bus and to achieve a bidirectional power flow for the SC, a wide voltage conversion 
ratio bidirectional DC-DC converter is needed. Considering that the SC needs to compensate for transient power, the bidirectional DC-DC converter needs to have the feature of an outstanding dynamic response.

Many isolated and non-isolated bidirectional converters present in the literature can achieve a wide voltage conversion ratio. Due to using a high-frequency transformer, the isolated bidirectional converters can obtain a wide voltage conversion ratio in the step-up and step-down modes by adjusting the turns ratio of the transformer. Because of the use of a transformer and a high number of switching devices, the cost and switching losses of these converters will be increased and the control schemes will be more complicated [17-20]. From the viewpoint of system cost-saving and improving system efficiency, a non-isolated DC-DC converter is more suitable for HESS applications [21,22].

Research on non-isolated converters is focused on coupled-inductor, switched-capacitor, switchedinductor, voltage-multiplier, and multi-stage/-level techniques [23]. The coupled-inductor-based converter in [24] can have a higher voltage gain, and also reduce the reverse recovery losses of the diodes. However, the current ripple of the low-voltage side is relatively large, which may damage the low-voltage side source. With a simple structure, switched-capacitor converters are easy to expand. At the same time, the control methods of these converters are also simple. In different switching states, the energy of the capacitors in these converters can be delivered through different paths, making it easier for these converters to achieve a high voltage gain [25-28]. Switched-inductor converters can also achieve a wide voltage conversion ratio while avoiding extreme duty cycles. At the same time, the voltage stress of the power semiconductors in these converters can be reduced. However, more inductors affect the power density of these converters [29,30]. In [31], a new non-isolated single capacitor bidirectional DC-DC converter with a simple structure and a wide voltage conversion ratio is presented. However, the voltage stress of the power semiconductor is relatively high. A common ground switched-quasi-Z-source bidirectional DC-DC converter is presented in [32]. The advantages of this converter are a wide voltage conversion ratio and a lower voltage stress across the power switches. However, with the low voltage level $(240 \mathrm{~V})$ and low rated power $(300 \mathrm{~W})$, the volume of the capacitors $(470 / 520 \mathrm{uF})$ and inductors $(434 / 600 \mathrm{uH})$ is high, which results in a lower power density for this converter.

This paper presents a novel common grounded H-type bidirectional DC-DC converter, which not only achieves a wide voltage conversion ratio, but also has the advantages of a low inductor current ripple and a good dynamic response. In addition, a clamp capacitor is used in this converter to keep all of the power switches turned on and off only once during each switching period, aiming at reducing switching losses and avoiding narrow pulses of the pulse width modulation (PWM) voltage waveform at high voltage gain. These features are beneficial to improve the efficiency and reliability of this converter and its suitability for HESS applications.

As shown in Figure 1, a HESS contains a battery and an SC. The SC outputs are varying low dc voltages $(25-60 \mathrm{~V})$ which cannot be used directly, and must be regulated via the bidirectional converter. The proposed converter can fulfill the task well. The remainder of this paper is structured as follows. In Section 2, the novel H-type bidirectional DC-DC converter topology and operating principles are proposed. In Section 3, the characteristics of the proposed converter are analyzed and its small signal model is established. Experimental results for the proposed converter are provided in Section 4. The conclusion of this paper is introduced in Section 5. 


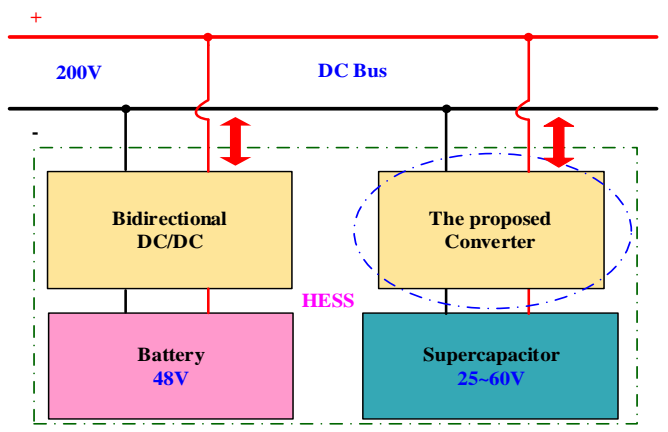

Figure 1. Configuration of the hybrid energy storage system (HESS). DC: direct current.

\section{Operating Principles of the Proposed Converter}

\subsection{Configuration of the Proposed Converter}

The configuration of the proposed converter is depicted in Figure 2. This converter is composed of a capacitor-clamped $H$-type structure $\left(Q_{1}-Q_{4}\right.$ and $\left.C_{1}\right)$, an inductor, a power switch $Q_{5}$, and two filter capacitors $C_{\text {high }}$ and $C_{\text {low }}$. To simplify the analysis, it is assumed that the capacitors and inductor are large enough and all of the power semiconductors are ideal. In order to protect the SC, the proposed converter operates in the input current continuous model (CCM).

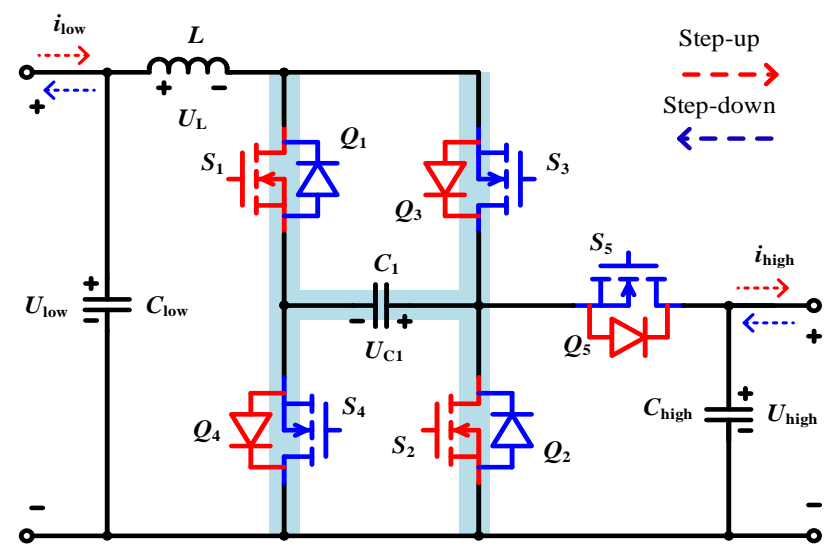

Figure 2. Configuration of the proposed converter.

\subsection{Operating Principles}

\subsubsection{Step-Up Mode of the Proposed Converter}

As shown in Figure 2, $U_{\text {low }}$ can be stepped-up to $U_{\text {high }}$ by controlling the power semiconductors $Q_{1}$, and $Q_{2}$. The relationship between $d_{1}$ and $d_{2}$ can be written as $d_{1}=d_{2}=d_{\text {Boost }}$, where $d_{1}$ and $d_{2}$ are the duty cycles of $Q_{1}$ and $Q_{2}$, respectively. The phase difference between the gate-driving signals $S_{1}$ and $S_{2}$ is $180^{\circ}$. During one switching period, the converter has three switching states, and their sequence is "10-00-01-00-10". Figure 3 shows the energy flow paths and Figure 4 shows the typical waveforms. Due to using the clamp capacitor $C_{1}$, all of the power semiconductors turn on and off only once during each switching period.

When $S_{1} S_{2}=10$ : As shown in Figure 3a, where switch $S_{1}$ is $O N$ and $S_{2}$ is OFF. The anti-parallel diodes of $Q_{4}$ and $Q_{5}$ are forward biased, while the anti-parallel diode of $Q_{3}$ is reverse biased. The inductor $L$ is charged from the input source. Current $i_{\mathrm{L}}$ rises linearly. The load is supplied by $C_{1}$ and $C_{\text {high }}$. Clamp capacitor $C_{1}$ maintains the forward bias of the anti-parallel diodes of $Q_{5}$. 
When $S_{1} S_{2}=00$ : As shown in Figure 3b, both switches $S_{1}$ and $S_{2}$ are OFF. The anti-parallel diodes of $Q_{3}, Q_{4}$, and $Q_{5}$ are forward biased. Capacitors $C_{1}$ and $C_{\text {high }}$ are charged from $L$. The load is supplied by $L$. There is no energy exchange between capacitors $C_{1}$ and $C_{\text {high }}$.

When $S_{1} S_{2}=01$ : As shown in Figure 3c, where switch $S_{1}$ is OFF and $S_{2}$ is ON. The anti-parallel diode of $Q_{3}$ is forward biased, while the anti-parallel diodes of $Q_{4}$ and $Q_{5}$ are reverse biased. Inductor $L$ is charged from the input source. Current $i_{\mathrm{L}}$ rises linearly. The load is supplied by output capacitor $C_{\text {high }}$. In this case, the voltage of capacitor $C_{1}$ remains steady.

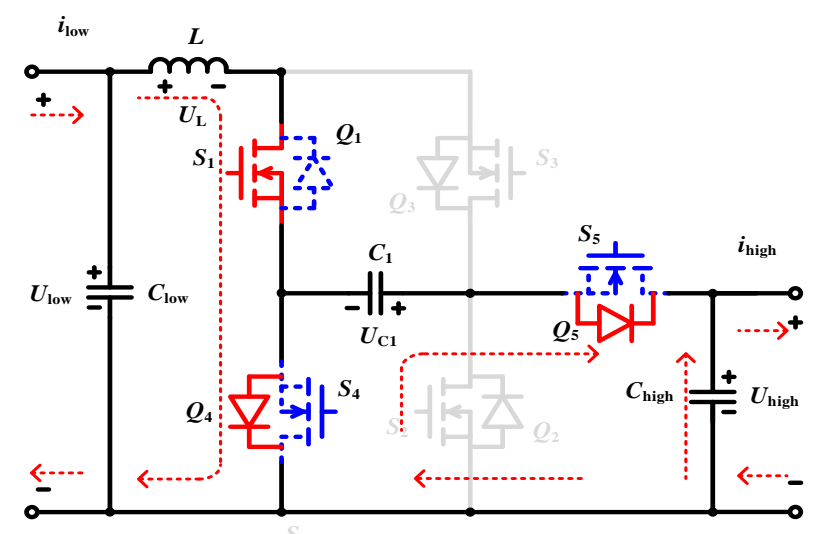

(a)

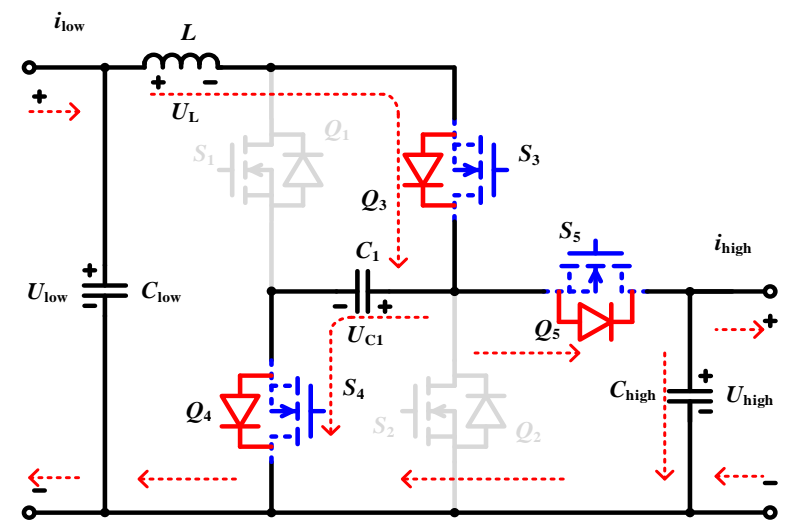

(b)

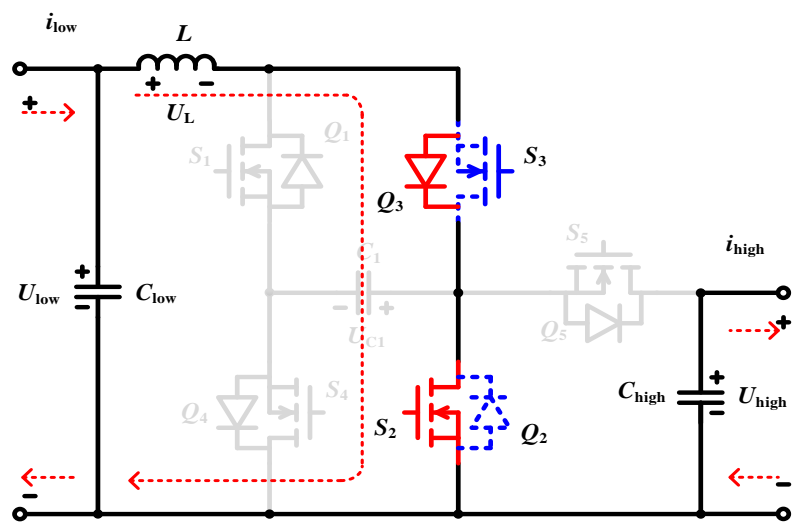

(c)

Figure 3. Energy flow paths of the proposed converter in the step-up mode; (a) $S_{1} S_{2}=10$; (b) $S_{1} S_{2}=00$; (c) $S_{1} S_{2}=01$. 


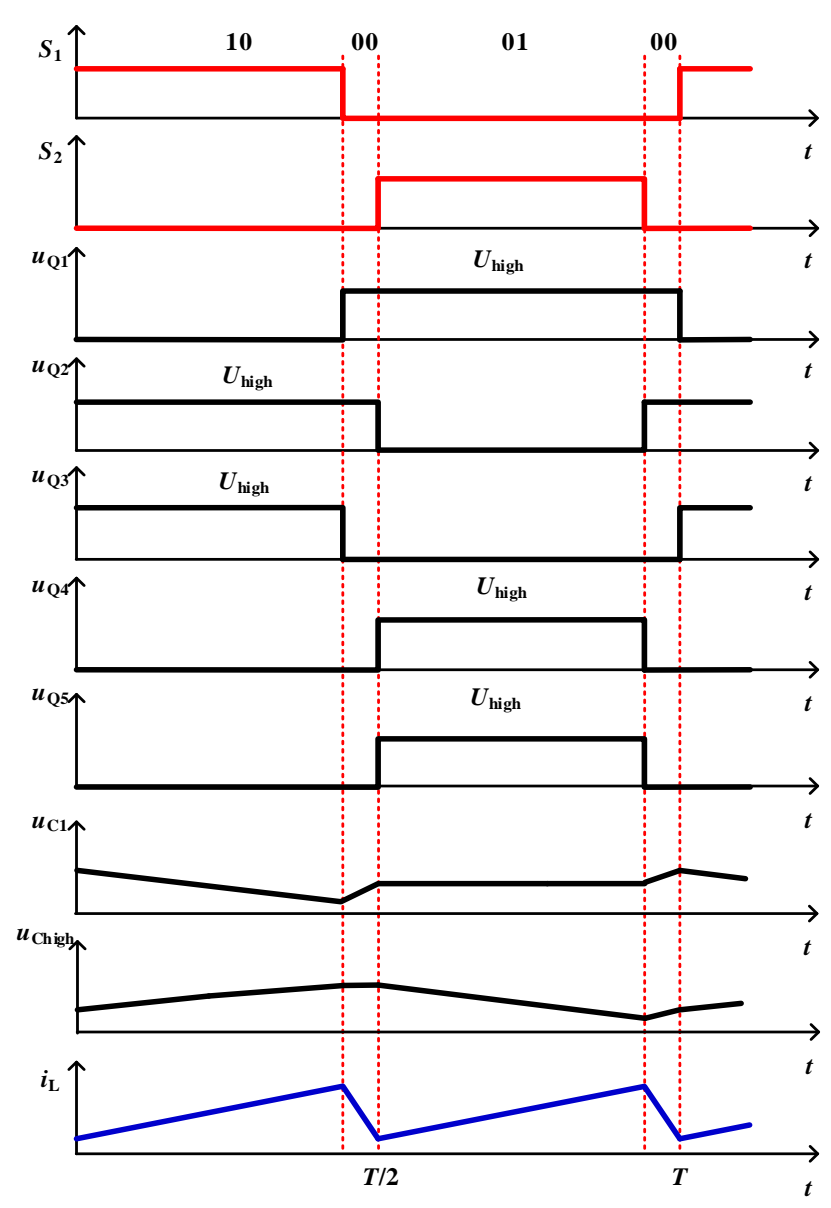

Figure 4. Typical waveforms of the proposed converter in the step-up mode.

\subsubsection{Step-Down Mode of the Proposed Converter}

As shown in Figure 2, $U_{\text {high }}$ can be stepped down to $U_{\text {low }}$ by controlling the power semiconductors $Q_{3}, Q_{4}$, and $Q_{5}$. The relationship between $d_{3}, d_{4}$, and $d_{5}$ can be written as $d_{3}=d_{4}=d_{5}=d_{\text {Buck }}$, where $d_{3}$, $d_{4}$, and $d_{5}$ are the duty cycles of $Q_{3}, Q_{4}$, and $Q_{5}$, respectively. The phase difference between the gate-driving signals $S_{3}$ and $S_{4}$ is $180^{\circ}$. The gate-driving signal $S_{5}=S_{4}$. During one switching period, the converter has three switching states, and their sequence is "111-100-111-011-111". Figure 5 shows the energy flow paths and Figure 6 shows the typical waveforms. During each switching period, all of the power semiconductors also turn on and off once.

When $S_{3} S_{4} S_{5}=111$ : The switching state is shown in Figure 5 a, where switches $S_{3}, S_{4}$, and $S_{5}$ are $O N$. The anti-parallel diodes of $Q_{1}$ and $Q_{2}$ are forward biased. The high-voltage side $U_{\text {high }}$ and capacitor $C_{1}$ charge the inductor $L$, and simultaneously provide energy to the load in the low-voltage side. The current $i_{\mathrm{L}}$ rises linearly.

When $S_{3} S_{4} S_{5}=100$ : The switching state is shown in Figure $5 \mathrm{~b}$, where switch $S_{3}$ is $O N$ and switches $S_{4}$ and $S_{5}$ are OFF. The anti-parallel diode of $Q_{2}$ is forward biased, while the anti-parallel diode of $Q_{1}$ is reverse biased. Inductor $L$ provides energy to the load in the low-voltage side. The current $i_{\mathrm{L}}$ decreases linearly.

When $S_{3} S_{4} S_{5}=011$ : The switching state is shown in Figure $5 c$, where switches $S_{4}$ and $S_{5}$ are $O N$ and $S_{3}$ is OFF. The anti-parallel diode of $Q_{1}$ is forward biased, while the anti-parallel diode of $Q_{2}$ is reverse biased. Inductor $L$ provides energy to the load in the low-voltage side. The current $i_{\mathrm{L}}$ decreases linearly. Capacitor $C_{1}$ is charged by the high-voltage side $U_{\text {high }}$. The clamp capacitor $C_{1}$ maintains the power switch $Q_{5} O N$. 


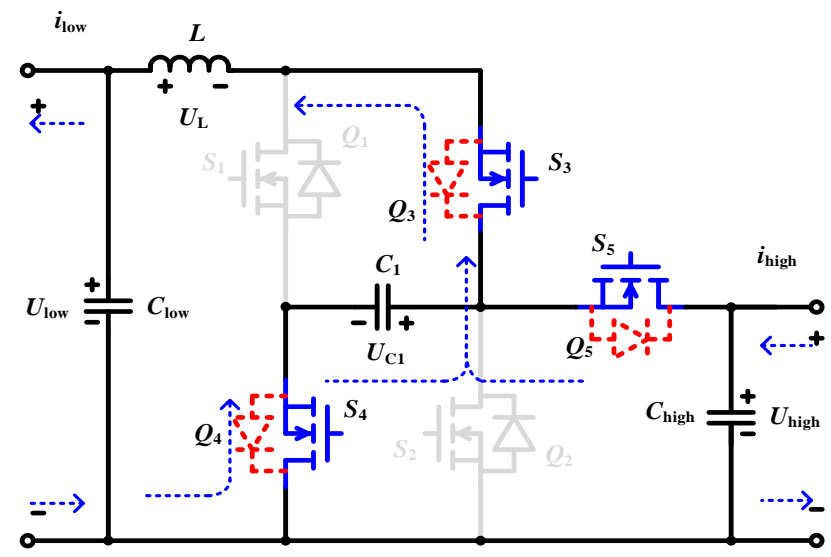

(a)

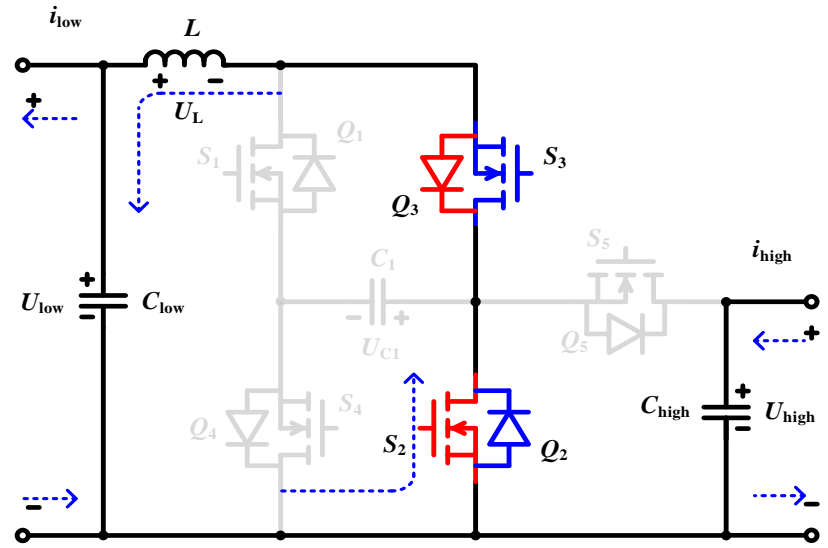

(b)

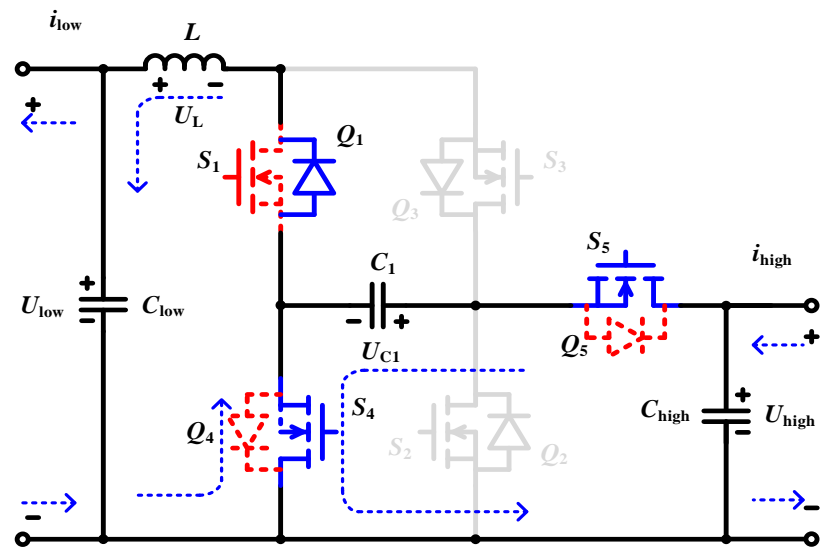

(c)

Figure 5. Energy flow paths of the proposed converter in the step-down mode; (a) $S_{3} S_{4} S_{5}=111$; (b) $S_{3} S_{4} S_{5}=100 ;$ (c) $S_{3} S_{4} S_{5}=011$. 


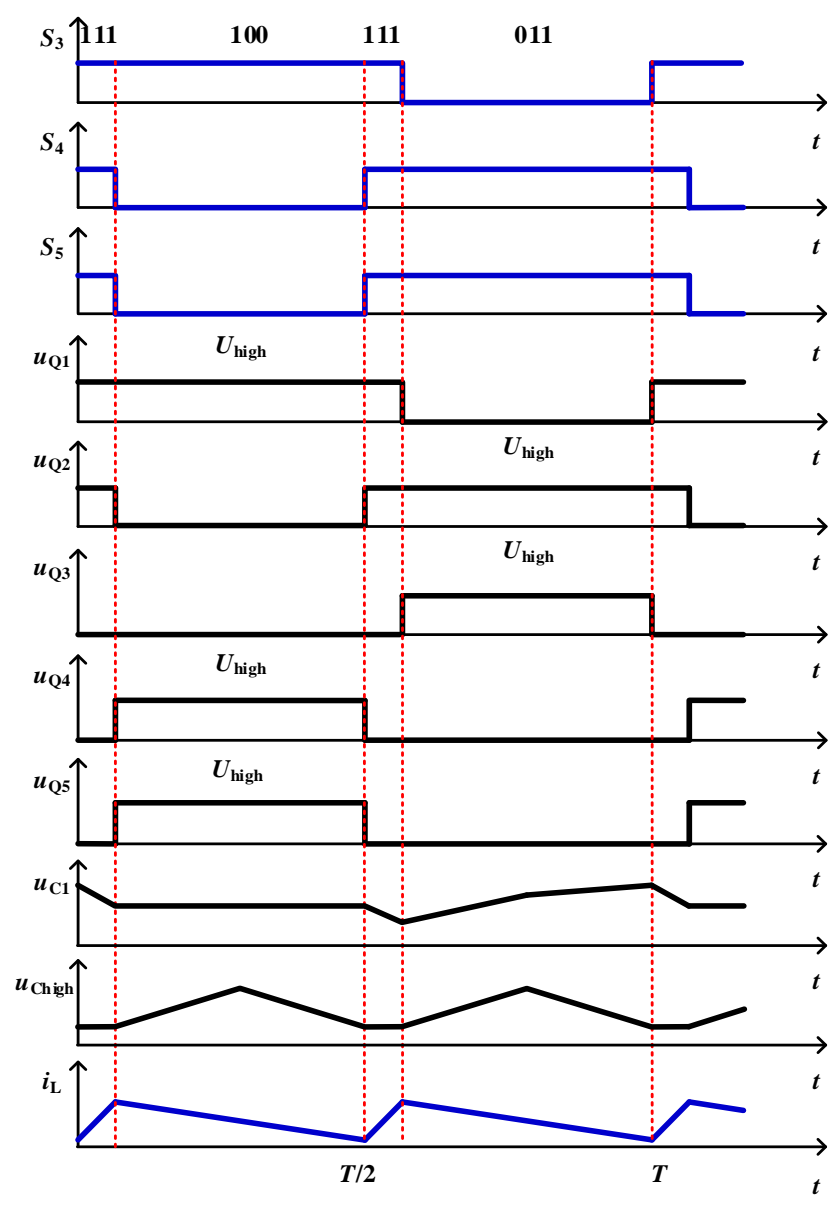

Figure 6. Typical waveforms of the proposed converter in the step-down mode.

\subsubsection{Synchronous Rectification Mode of the Proposed Converter}

The on-state resistance of the power switch is lower than its corresponding anti-parallel diode. As mentioned above, current flow into the corresponding anti-parallel diodes of the slave power switches will result in higher conduction losses and lower efficiency. In order to improve the efficiency, the proposed converter uses synchronous rectifier technology [33,34].

The synchronous rectification operation principle of the proposed converter is shown in Figure 7. Figure 7a shows the gate signals of $S_{1}-S_{5}$ in step-up mode and Figure $7 \mathrm{~b}$ shows the gate signals of $S_{1}-S_{5}$ in step-down mode. In step-up mode, the current has to fully flow into the corresponding anti-parallel diodes of the slave power switches $Q_{3}, Q_{4}$, and $Q_{5}$ at the dead time $t_{\mathrm{d}}$. When the slave power switches are $O N$, the current almost flows into the MOSFETS due to their lower on-resistance as shown in Figure 7c. In step-down mode, the current flow path is the same as with the step-up mode as shown in Figure 7d. The only difference is that the slave power switches are $Q_{1}$ and $Q_{2}$.

When the current flows into the corresponding anti-parallel diodes of the slave power switches at dead time, the forward voltage drops of the anti-parallel diodes are close to zero. As a result, the slave active power switches turn on and turn off with zero voltage. The turn on/off losses of the slave active power switches will not be increased and the efficiency of the converter can be improved. 


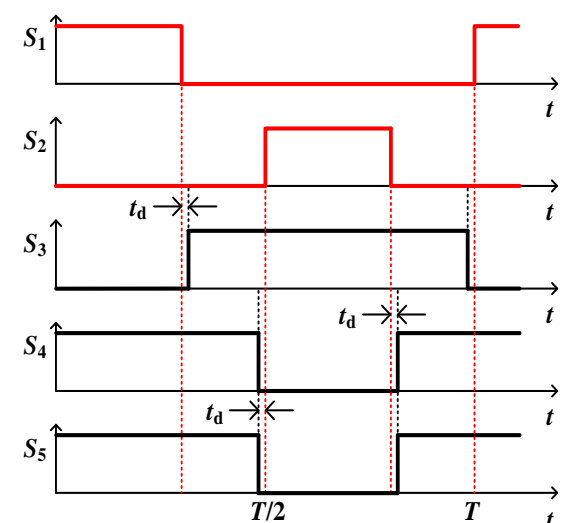

(a)

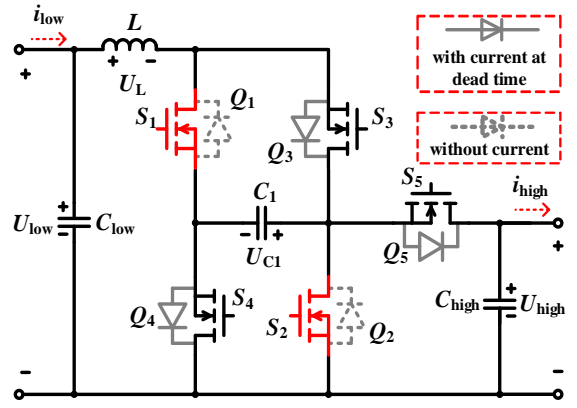

(c)

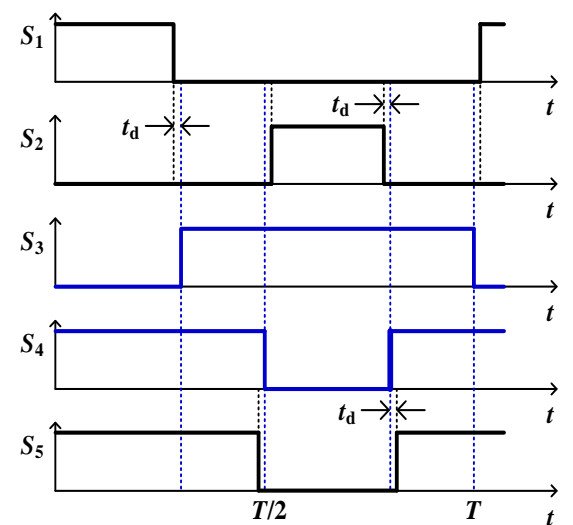

(b)

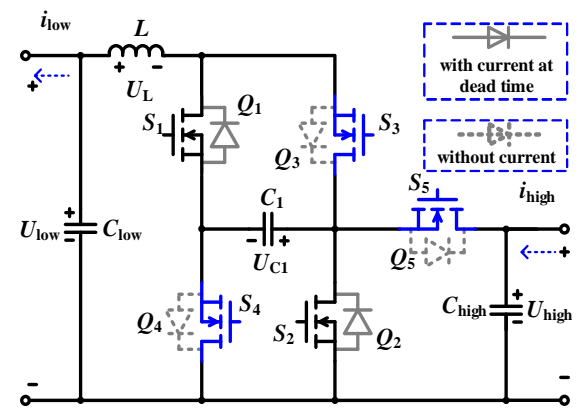

(d)

Figure 7. Synchronous rectification operation principle of the proposed converter; (a) Gate signals and dead time in step-up mode; (b) Gate signals and dead time in step-down mode; (c) Current flow path in step-up mode; (d) Current flow path in step-down mode.

\subsection{Control Strategy for Bidirectional Power Flow}

For a HESS, the SC interface converter should be able to respond to fast bidirectional power fluctuations immediately. Therefore, a virtual capacitor droop (VCD) control is adopted for this converter. At the same time, the battery interface converter uses a virtual resistance droop (VRD) control to make the battery provide total power at steady state. Due to using the VCD and VCR control, the HESS can adapt to the distributed nature of the DC micro-grid and increase system reliability and scalability $[35,36]$. The specific control strategy is shown in Figure 8. As shown in Figure 8, the voltage controller is used to follow the reference voltage $U_{\text {ref. }}$. The voltage $U_{\text {high }}$ and the currents $i_{\text {high-sc }}$ and $i_{\text {high-bat }}$ are obtained by the sensor samplings. $i_{\text {high-sc }}$ refers to the output current of the SC interface converter and $i_{\text {high-bat }}$ refers to the output current of the battery interface converter.

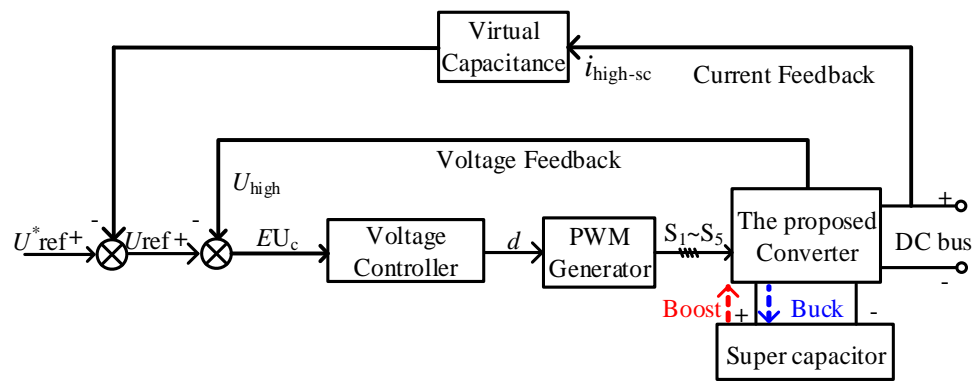

(a)

Figure 8. Cont. 


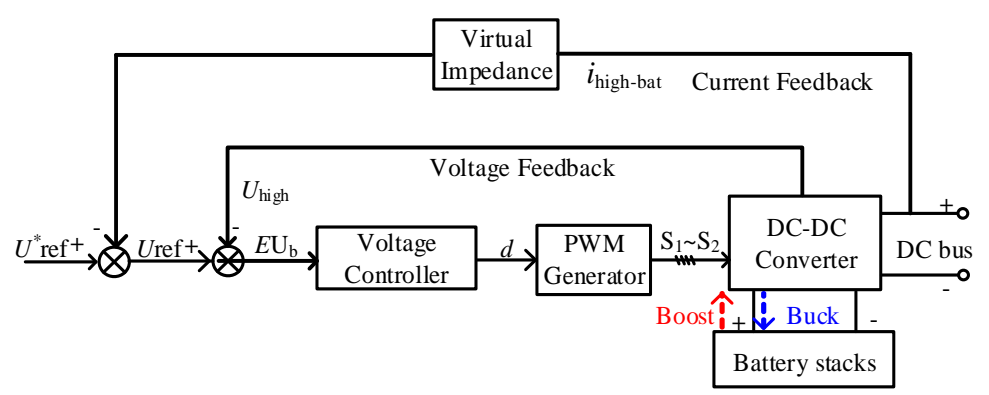

(b)

Figure 8. Control strategy for bidirectional power flow; (a) virtual capacitor droop (VCD) control; (b) virtual resistance droop (VRD) control.

The operation modes of the proposed converter switch between the step-down and step-up modes according to the necessary conditions of a general load. The current relationship at the DC bus is expressed as

$$
i_{\text {HESS }}=i_{\text {high-sc }}+i_{\text {high-bat }}
$$

where $i_{\text {HESS }}$ is the equivalent load current of the HESS and can be either positive or negative. The output voltage-current (V-I) relationship of the battery interface converter under the VRD control and that of the SC interface converter under the VCD control are given by

$$
\left\{\begin{array}{l}
U_{\text {high }}=U *_{\text {ref }}-R_{\mathrm{vb}} i_{\text {high-bat }} \\
U_{\text {high }}=U *_{\text {ref }}-\frac{1}{s C_{\mathrm{vc}}} i_{\text {high-sc }}
\end{array}\right.
$$

where $R_{\mathrm{vb}}$ is the virtual resistance and $C_{\mathrm{vc}}$ is the virtual capacitance. Based on (1) and (2), the currentsharing relationship between battery and SC is derived as

$$
\left\{\begin{array}{l}
i_{\text {high }- \text { bat }}=\frac{1}{s R_{\mathrm{vb}} C_{\mathrm{vc}}+1} i_{\mathrm{HESS}} \\
i_{\text {high }-\mathrm{sc}}=\frac{s R_{\mathrm{vb}} C_{\mathrm{vc}}}{s R_{\mathrm{vb}} C_{\mathrm{vc}}+1} i_{\mathrm{HESS}}
\end{array} .\right.
$$

\section{Characteristics of the Proposed Converter}

\subsection{Wide Voltage Conversion Ratio}

\subsubsection{Voltage Conversion Ratio in Step-Up Mode}

For the proposed converter shown in Figure 2, the voltage conversion ratio can be derived from the volt-sec balance of the inductor $L$. According to Figure $3 a, Q_{4}$ and $Q_{5}$ are $O N$, so that the voltages of $C_{1}$ and $C_{\text {high }}$ are equal. In the low-voltage side current continuous model, the equations can be obtained as follows:

$$
\left\{\begin{array}{l}
2 U_{\text {low }} d_{\text {Boost }}+\left(U_{\text {low }}-U_{\text {high }}\right)\left(1-2 d_{\text {Boost }}\right)=0 \\
U_{\mathrm{C} 1}=U_{\text {high }}
\end{array}\right.
$$

where $U_{\mathrm{C} 1}$ is the voltage over $C_{1}$. By simplifying (1), the following equation can be derived:

$$
\left\{\begin{array}{l}
U_{\text {high }}=\frac{1}{1-2 d_{\text {Boost }}} U_{\text {low }} \\
U_{\mathrm{C} 1}=U_{\text {high }}
\end{array} .\right.
$$

The voltage conversion ratio $M_{\text {Boost }}$ of the proposed converter is 


$$
M_{\text {Boost }}=\frac{1}{1-2 d_{\text {Boost }}}
$$

where $0<d_{\text {Boost }}<0.5$.

\subsubsection{Voltage Conversion Ratio in Step-Down Mode}

According to Figure $5 \mathrm{c}$, the power switches $Q_{4}$ and $Q_{5}$ are $O N$, so that the voltages of $C_{1}$ and $C_{\text {high }}$ are equal. By applying the volt-second balance principle on $L$, the voltage conversion ratio in CCM can be obtained as

$$
\left\{\begin{array}{l}
\left(U_{\text {low }}-U_{\text {high }}\right)\left(2 d_{\text {Buck }}-1\right)+2 U_{\text {low }}\left(1-d_{\text {Buck }}\right)=0 \\
U_{\mathrm{C} 1}=U_{\text {high }}
\end{array} .\right.
$$

By simplifying (7), the following equation can be derived:

$$
\left\{\begin{array}{l}
U_{\text {low }}=\left(2 d_{\text {Buck }}-1\right) U_{\text {high }} \\
U_{\mathrm{C} 1}=U_{\text {high }}
\end{array}\right.
$$

The voltage conversion ratio $M_{\text {Buck }}$ in step-down mode is

$$
M_{\text {Buck }}=2 d_{\text {Buck }}-1
$$

where $0.5<d_{\text {Buck }}<1$.

Under the same voltage conversion ratio, 0 shows the comparison between the proposed and the traditional two-level bidirectional converters. According to Figure 9, when the voltage conversion ratio is 8 in the step-up mode, the duty cycles of the proposed and the traditional converters are 0.4375 and 0.875 , respectively; in step-down mode, when the voltage conversion ratio is 0.125 , the duty cycles of the proposed and the traditional converters are 0.5625 and 0.125 , respectively. Compared with the traditional converter, the proposed one can avoid the extreme duty cycle while achieving a high voltage conversion ratio. What is more, the higher the voltage conversion ratio, the closer the duty cycle is to 0.5 . When the duty cycle approaches 0.5 , the time used to maintain the ON and OFF state for all power semiconductors is nearly equal in each period, which is beneficial to avoid the narrow pulse of PWM voltage waveforms while the high voltage conversion ratio is achieved.

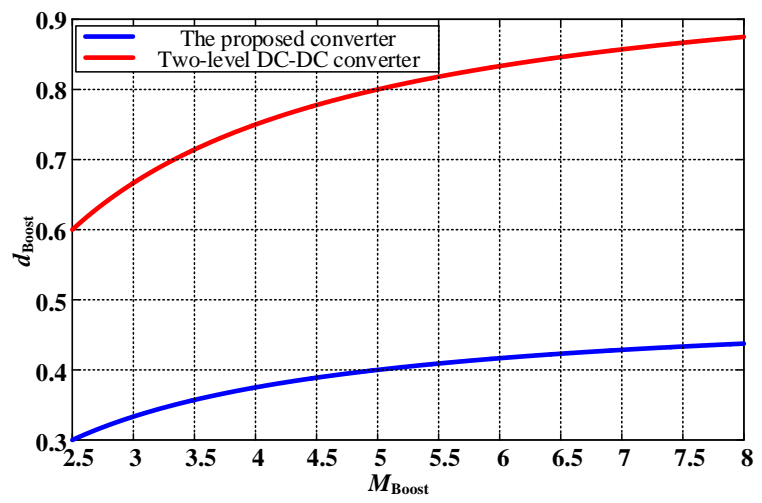

(a)

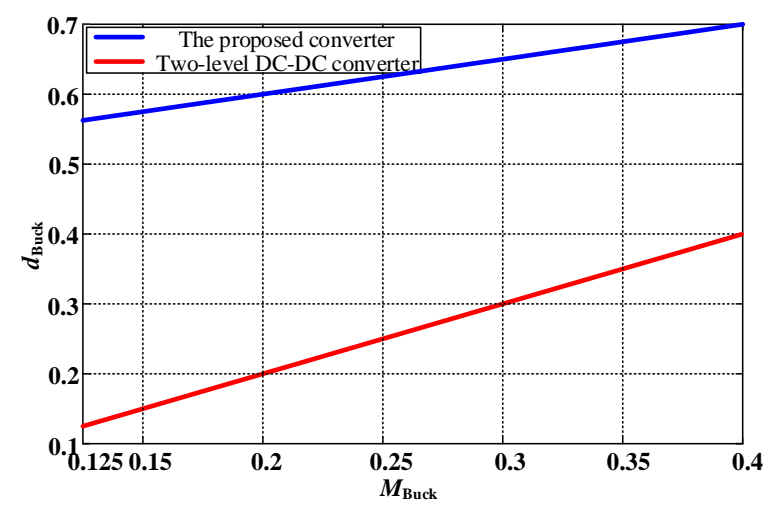

(b)

Figure 9. Comparisons of duty cycle against voltage gain; (a) Step-up mode; (b) Step-down mode. 


\subsection{Low Inductor Current Ripple}

\subsubsection{The Average Inductor Current and Inductor Current Ripple in Step-Up Mode}

The average inductor current can be derived from the ampere-second balance of the capacitors $C_{1}$ and $C_{\text {high }}$ in CCM.

$$
\left\{\begin{array}{l}
d_{\text {Boost }} I_{\text {c1a }}+\left(1-2 d_{\text {Boost }}\right) I_{\mathrm{clb}}=0 \\
-d_{\text {Boost }}\left(2 I_{\text {high }}+I_{\text {c1a }}\right)+\left(1-2 d_{\text {Boost }}\right)\left(I_{\mathrm{L}}-I_{\text {high }}-I_{\mathrm{clb}}\right)=0
\end{array}\right.
$$

where $I_{\mathrm{C} 1 \mathrm{a}}$ and $I_{\mathrm{C} 1 \mathrm{~b}}$ are the average currents across $C_{1}$ in state 10 and 00 , respectively. It follows from (10) that the average inductor current $I_{\mathrm{L}}$ can be obtained as follows:

$$
I_{\mathrm{L}}=\frac{1}{1-2 d_{\text {Boost }}} \times I_{\text {high }} .
$$

In the state 10, the inductor current increases linearly, and (12) can be obtained as

$$
i_{\mathrm{L}\left(d_{\text {Boost }} T\right)}=i_{\mathrm{L}(0)}+\frac{1}{L} \int_{0}^{d_{\text {Boost }} T} U_{\text {low }} d t \Rightarrow \Delta i_{\mathrm{L}}=\frac{1}{L} \int_{0}^{d_{\text {Boost }} T} U_{\text {low }} d t=\frac{d_{\text {Boost }} \times U_{\text {low }}}{L f}
$$

where $f$ is the switching frequency and $\Delta i_{\mathrm{L}}$ is the inductor current ripple. It follows from (11) and (12) that the current ripple ratio $r_{\text {Boost }}$ of the inductor can be obtained as

$$
r_{\text {Boost }}=\frac{\Delta i_{\mathrm{L}}}{I_{\mathrm{L}}}=\frac{d_{\text {Boost }}\left(1-2 d_{\text {Boost }}\right)^{2} \times R_{\text {high }}}{L f}
$$

where $R_{\text {high }}$ is the equivalent load of the high-voltage side.

\subsubsection{The Average Inductor Current and Inductor Current Ripple in Step-Down Mode}

The average inductor current $I_{\mathrm{L}}$ can be obtained as follows:

$$
I_{\mathrm{L}}=I_{\mathrm{low}}
$$

In the state 100, the inductor current decreases linearly, and (15) can be obtained as

$$
i_{\mathrm{L}\left(d_{\text {Buck }} T\right)}=i_{\mathrm{L}(0)}+\frac{1}{L} \int_{\left(d_{\text {Buck }}-0.5\right) T}^{0.5 T} U_{\text {low }} d t \Rightarrow \Delta i_{\mathrm{L}}=\frac{1}{L} \int_{\left(d_{\text {Buck }}-0.5\right) T}^{0.5 T} U_{\text {low }} d t=\frac{\left(1-d_{\text {Buck }}\right) \times U_{\text {low }}}{L f} .
$$

It follows from (14) and (15) that the current ripple ratio $r_{\text {Buck }}$ of the inductor can be obtained as follows:

$$
r_{\text {Buck }}=\frac{\Delta i_{\mathrm{L}}}{I_{\mathrm{L}}}=\frac{\left(1-d_{\text {Buck }}\right) \times R_{\text {low }}}{L f}
$$

where $R_{\text {low }}$ is the equivalent load of the low-voltage side.

The inductor current ripple ratios of a traditional two-level bidirectional converter are:

$$
\left\{\begin{array}{l}
r \prime_{\text {Boost }}=\frac{d{ }_{\text {Boost }}\left(1-d \prime_{\text {Boost }}\right)^{2} \times R_{\text {high }}}{L f} \\
r^{\prime}{ }_{\text {Buck }}=\frac{\left(1-d_{\text {Buck }}\right) \times R_{\text {low }}}{L f}
\end{array}\right.
$$

where $d{ }^{\text {Boost }}$ and $d_{\text {Buck }} /$ are the duty cycles of that converter in step-up and step-down mode, respectively. $r{ }^{\prime}$ Boost and $r{ }^{\prime}$ Buck are the current ripple ratios of that converter in step-up and step-down mode, respectively. 
Supposing that the output power, inductor, and switching frequency of the proposed converter and the traditional two-level converter are equal, it can be obtained that

$$
\frac{r_{\text {Boost }}}{r \prime_{\text {Boost }}}=\frac{r_{\text {Buck }}}{r \prime_{\text {Buck }}}=\frac{1}{2} .
$$

It can be concluded from (18) that the inductor current ripple ratio in the proposed converter is lower than that in the traditional two-level converter. On the other hand, if the inductor current ripple ratios are equal, the inductor of the proposed converter is only half that of the traditional one, which means that the proposed converter has outstanding dynamic response.

\subsection{Good Dynamic Performance}

The proposed converter can work in both the step-up and step-down modes. In order to save paper space, only the dynamic performance in step-down mode is analyzed. Before analyzing the dynamic performance, a small-signal model of step-down mode is needed.

When the proposed converter operates in the range $0.5<d_{\text {Buck }}<1$, the main power switches $Q_{3}$, $Q_{4}$, and $Q_{5}$ have three effective switching states: $S_{3} S_{4} S_{5}=[111,100,011] . u_{\text {high }}, u_{\text {low }}$, and $d_{\text {Buck }}$ are the input, the output, and the control variables, respectively. $i_{\mathrm{L}}, u_{\mathrm{C} 1}$, and $u_{\mathrm{Clow}}$ are the state variables. $r$ is the equivalent series resistance for $C_{1}$.

When $S_{3} S_{4} S_{5}=111$, the operating time of the proposed converter is $\left(2 d_{\text {Buck }}-1\right) \times$ T. The state space average model in this operating time is

$$
\left\{\begin{array}{l}
{\left[\begin{array}{c}
\dot{i}_{\mathrm{L}} \\
\dot{u}_{\mathrm{C}_{1}} \\
\dot{u}_{\text {Clow }}
\end{array}\right]=\left[\begin{array}{ccc}
0 & 0 & \frac{1}{L} \\
0 & -\frac{1}{C_{1} r} & 0 \\
-\frac{1}{C_{\text {low }}} & 0 & -\frac{1}{C_{\text {low }} R}
\end{array}\right]\left[\begin{array}{c}
i_{\mathrm{L}} \\
u_{\mathrm{C}_{1}} \\
u_{\text {Clow }}
\end{array}\right]+\left[\begin{array}{c}
-\frac{1}{L} \\
\frac{1}{C_{1} r} \\
0
\end{array}\right] u_{\text {high }}} \\
u_{\text {low }}=\left[\begin{array}{lll}
0 & 0 & 1
\end{array}\right]\left[\begin{array}{lll}
i_{\mathrm{L}} & u_{\mathrm{C}_{1}} & u_{\text {Clow }}
\end{array}\right]^{T}
\end{array}\right.
$$

When $S_{3} S_{4} S_{5}=100$, the operating time of the proposed converter is $\left(1-d_{\text {Buck }}\right) \times$ T. The state space average model in this operating time is

$$
\left\{\begin{array}{l}
{\left[\begin{array}{c}
\dot{i}_{\mathrm{L}} \\
\dot{u}_{\mathrm{C}_{1}} \\
\dot{u}_{\mathrm{Clow}}
\end{array}\right]=\left[\begin{array}{ccc}
0 & 0 & \frac{1}{L} \\
0 & 0 & 0 \\
-\frac{1}{C_{\text {low }}} & 0 & -\frac{1}{C_{\text {low }} R}
\end{array}\right]\left[\begin{array}{c}
i_{\mathrm{L}} \\
u_{\mathrm{C}_{1}} \\
u_{\mathrm{Clow}}
\end{array}\right]+\left[\begin{array}{l}
0 \\
0 \\
0
\end{array}\right] u_{\text {high }}} \\
u_{\text {low }}=\left[\begin{array}{lll}
0 & 0 & 1
\end{array}\right]\left[\begin{array}{lll}
i_{\mathrm{L}} & u_{\mathrm{C}_{1}} & u_{\text {Clow }}
\end{array}\right]^{T}
\end{array}\right.
$$

When $S_{3} S_{4} S_{5}=011$, the operating time of the proposed converter is $\left(1-d_{\text {Buck }}\right) \times$ T. The state space average model in this operating time is

$$
\left\{\begin{array}{l}
{\left[\begin{array}{c}
\dot{i}_{\mathrm{L}} \\
\dot{u}_{\mathrm{C}_{1}} \\
\dot{u}_{\text {Clow }}
\end{array}\right]=\left[\begin{array}{ccc}
0 & 0 & \frac{1}{L} \\
0 & -\frac{1}{C_{1} r} & 0 \\
-\frac{1}{C_{\text {low }}} & 0 & -\frac{1}{C_{\text {low }} R}
\end{array}\right]\left[\begin{array}{c}
i_{\mathrm{L}} \\
u_{\mathrm{C}_{1}} \\
u_{\text {Clow }}
\end{array}\right]+\left[\begin{array}{c}
0 \\
\frac{1}{C_{1} r} \\
0
\end{array}\right] u_{\text {high }}} \\
u_{\text {low }}=\left[\begin{array}{lll}
0 & 0 & 1
\end{array}\right]\left[\begin{array}{lll}
i_{\mathrm{L}} & u_{\mathrm{C}_{1}} & u_{\text {Clow }}
\end{array}\right]^{T}
\end{array}\right.
$$


Combining (19) and (20) with (21), the average model of the proposed converter is

$$
\left\{\begin{array}{l}
{\left[\begin{array}{c}
\dot{i}_{\mathrm{L}} \\
\dot{u}_{\mathrm{C}_{1}} \\
\dot{u}_{\text {Clow }}
\end{array}\right]=\left[\begin{array}{ccc}
0 & 0 & \frac{1}{L} \\
0 & -\frac{d_{\text {Buck }}}{C_{1} r} & 0 \\
-\frac{1}{C_{\text {low }}} & 0 & -\frac{1}{C_{\text {low }} R}
\end{array}\right]\left[\begin{array}{c}
i_{\mathrm{L}} \\
u_{\mathrm{C}_{1}} \\
u_{\text {Clow }}
\end{array}\right]+\left[\begin{array}{c}
\frac{1-2 d_{\text {Buck }}}{L} \\
\frac{d_{\text {Buck }}}{C_{1} r} \\
0
\end{array}\right] u_{\text {high }}} \\
u_{\text {low }}=\left[\begin{array}{lll}
0 & 0 & 1
\end{array}\right]\left[\begin{array}{lll}
i_{\mathrm{L}} & u_{\mathrm{C}_{1}} & u_{\text {Clow }}
\end{array}\right]^{T}
\end{array}\right.
$$

The state, the input, the output, and the control variables can be described by using the small-signal disturbance variables as:

$$
\left\{\begin{array}{l}
i_{\mathrm{L}}=I_{\mathrm{L}}+\hat{i}_{\mathrm{L}} \\
u_{\mathrm{C} 1}=U_{\mathrm{C} 1}+\hat{u}_{\mathrm{C} 1} \\
u_{\mathrm{Clow}}=U_{\text {Clow }}+\hat{u}_{\mathrm{Clow}} \\
u_{\text {high }}=U_{\text {high }}+\hat{u}_{\text {high }} \\
u_{\text {low }}=U_{\text {low }}+\hat{u}_{\text {low }} \\
d_{\text {Buck }}=D_{\text {Buck }}+\hat{d}_{\text {Buck }}
\end{array}\right.
$$

where $I_{\mathrm{L}}, U_{\mathrm{C} 1}, U_{\mathrm{Clow}}, U_{\text {low }}, U_{\text {high, }}$ and $D_{\text {Buck }}$ are steady state components, and $\hat{i}_{\mathrm{L}}, \hat{u}_{\mathrm{C} 1}, \hat{u}_{\mathrm{Clow}}, \hat{u}_{\text {low }}$, and $\hat{d}_{\text {Buck }}$ are their corresponding small-signal disturbance variables.

As a result, the small-signal model of the proposed converter is

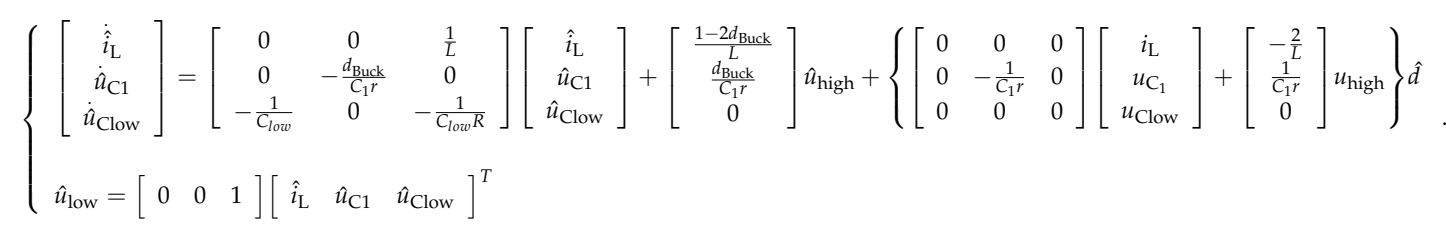

Using the parameters shown in Table 1, when the output voltage is $25 \mathrm{~V}$, the control-to-output transfer function can be expressed as

$$
G_{C}=\left.\frac{\hat{u}_{\text {low }}(s)}{\hat{d}_{\text {Buck }}(s)}\right|_{\hat{u}_{\text {high }}(s)=0}=\frac{6.52 \times 10^{7} s+1.5 \times 10^{13}}{s^{3}+3.32 \times 10^{5} s^{2}+2.55 \times 10^{8} s+7.52 \times 10^{12}} .
$$

Assume that the proposed converter and the traditional two-level converter have the same output power, inductor current ripple ratio, and switching frequency. Then, the inductor of the traditional two-level converter is double that of the proposed converter. The control-to-output transfer function of the traditional two-level converter in step-down mode can be expressed as

$$
G_{C^{\prime}}=\left.\frac{\hat{u}_{\text {low }}(s)}{\hat{d}_{\text {Buck }}(s)}\right|_{\hat{u}_{\text {high }}(s)=0}=\frac{200}{6.14 \times 10^{-8} s^{2}+59 \times 10^{-6} s+1} .
$$

The Bode diagram of the duty cycle to output voltage open-loop transfer function is shown in Figure 10. According to Figure 10, the crossover frequency of the proposed converter is higher than that of the traditional two-level converter due to smaller inductance. 


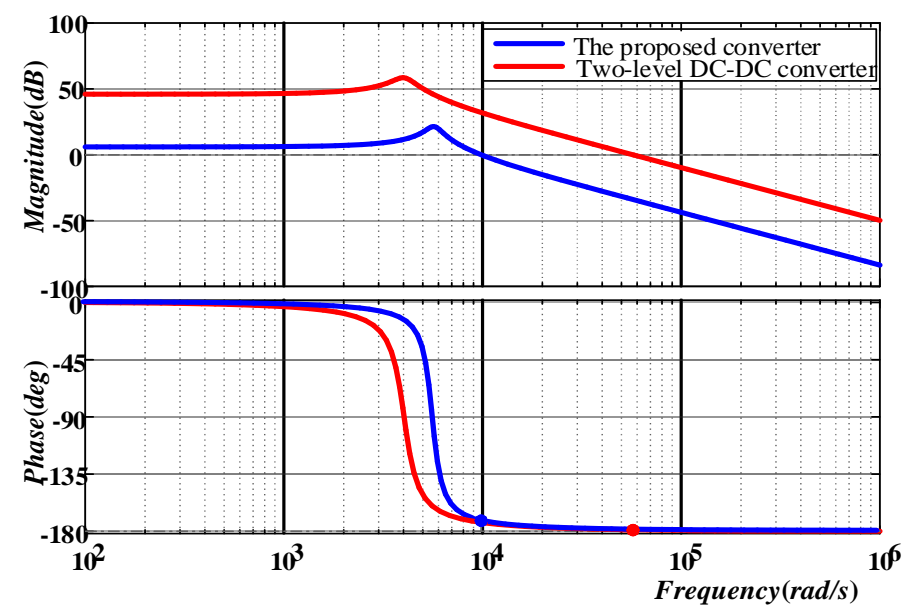

Figure 10. Bode diagram of the open-loop system.

The switching frequency of the traditional two-level converter can be chosen to be five times the crossover frequency. At this point, the equivalent switching frequency of the proposed converter is twice that of the switching frequency. The side-band effect has been eliminated due to interleave control. Therefore, the crossover frequency of the proposed converter can be increased to two-fifths of $f$. It means that the proposed converter can push to a higher control bandwidth, which leads to better dynamic performance.

In step-up mode, small inductance and a higher equivalent switching frequency lead to better dynamic performance too.

The control-to-output transfer function derived above is helpful to design the voltage controller shown in Figure 8. The voltage controller is a PI (proportional integral) regulator and it can be expressed as

$$
G_{\mathrm{PI}}(s)=k_{p}+k_{i} \frac{1}{s} .
$$

Using the control-to-output transfer function, $k_{\mathrm{p}}$ and $k_{\mathrm{i}}$ can be deduced.

Due to the use of the capacitor-clamped $\mathrm{H}$-type structure, the proposed converter has the following advantages:

- Avoiding the narrow pulse of PWM voltage waveforms when a high voltage conversion ratio is achieved: It costs a little time to turn a power semiconductor on and off, thus the ideal narrow pulse of the PWM voltage waveform is difficult to realize. The higher the voltage conversion ratio of the proposed converter is, the closer the duty cycle is to 0.5 . When the duty cycle approaches 0.5 , the time used to maintain the $O N$ and $O F F$ state for all power semiconductors is nearly equal in each period, which is beneficial to avoid the narrow pulse of PWM voltage waveforms while a high voltage conversion ratio is achieved.

- $\quad$ Reducing inductor current ripple: The inductor $L$ is charged and discharged twice during each switching period, as 0 and 0 show. With a small duty cycle in step-up mode, the charging time of the inductor is short. The charging time of the inductor in step-down mode is short too. Then, the inductor current ripple will decrease.

- Good dynamic performance: Due to using small inductance and a higher equivalent switching frequency, the proposed converter has a better dynamic performance. 


\subsection{Voltage and Current Stress on the Power Switches}

According to the current flow path of the proposed converter in step-up mode, as shown in 0 (or the current-flow path of the step-down mode, as shown in Figure 5), using the KVL (Kirchhoff's voltage law), the voltage stress on $Q_{1}-Q_{5}$ in the step-up and the step-down modes can be obtained as

$$
U_{\mathrm{Q} 1}=U_{\mathrm{Q} 2}=U_{\mathrm{Q} 3}=U_{\mathrm{Q} 4}=U_{\mathrm{Q} 5}=U_{\mathrm{high}} .
$$

The voltage stress on $Q_{1}-Q_{5}$ in the step-up and step-down modes is the same.

Similarly, according to current-flow path in step-up mode, as shown in Figure 3 (or the current-flow path in step-down mode, as shown in Figure 5), and the KCL (Kirchhoff's current law), the current stress (namely average currents when the switch is $O N$ ) on $Q_{1}-Q_{5}$ in the step-up and the step-down modes can be obtained as

$$
\left\{\begin{array}{l}
I_{\mathrm{Q} 1}=I_{\mathrm{Q} 2}=I_{\mathrm{Q} 3}=\frac{1}{1-2 d_{\text {Boost }}} \times I_{\text {high }} \\
I_{\mathrm{Q} 4}=\frac{d_{\text {Boost }}}{\left(1-d_{\text {Boost }}\right)\left(1-2 d_{\text {Boost }}\right)} \times I_{\text {high }} \\
I_{\mathrm{Q} 5}=\frac{1}{1-d_{\text {Boost }}} \times I_{\text {high }}
\end{array} .\right.
$$

The current stress on $Q_{1}-Q_{5}$ in the step-up and step-down modes is also identical.

\section{Experimental Result and Analyses}

In order to verify the feasibility of the theoretical analysis, an experimental prototype with the parameters shown in Table 1 has been developed.

Table 1. Experiment parameters.

\begin{tabular}{cc}
\hline Parameters & Values \\
\hline Rated power $P_{\mathrm{n}}$ & $320 \mathrm{~W}$ \\
Storage/filter capacitor $C_{\text {low }}$ and $C_{\text {high }}$ & $260 \mathrm{uF}$ \\
Clamp capacitor $C_{1}$ & $260 \mathrm{uF}$ \\
Storage/filter inductor $L$ & $114 \mathrm{uH}$ \\
High-voltage side $U_{\text {high }}$ & $200 \mathrm{~V}$ \\
Low-voltage side $U_{\text {low }}$ & $25 \sim 60 \mathrm{~V}$ \\
Switching frequency $f$ & $20 \mathrm{kHz}$ \\
Power semiconductors $Q_{1}-Q_{5}$ & IXTH $88 \mathrm{~N} 30 \mathrm{P}$ \\
\hline
\end{tabular}

\subsection{Experimental Results in the Step-Up Mode}

The PWM voltages of power semiconductors and the inductor current waveforms are shown in Figures 11 and 12. The PWM voltage of each power semiconductor is about $200 \mathrm{~V}$, approximately equal to the high-voltage side $U_{\text {high }}$, which validates the analysis in Section 3. According to Figures 11 and 12, the voltage gain $M_{\text {Boost }}$ of the proposed converter is 8 and the duty cycle $d_{\text {Boost }}$ is about 0.44 . The $O N$ state time of the power switches $Q_{1}-Q_{2}$ is about $0.44 \mathrm{~T}$ and the $O N$ state time of the power switches $Q_{3}-Q_{5}$ is about $0.56 \mathrm{~T}$. At that high voltage gain, both the $O N$ and $O F F$ state times of those power switches are close to $0.5 \mathrm{~T}$, which is effective for avoiding the narrow pulse of the PWM voltage waveforms. Due to using the synchronous rectification, the turn on and turn off of the controlled MOSFETs $Q_{3}, Q_{4}$, and $Q_{5}$ realize the ZVS (zero voltage switching), e.g., the gate signal $S_{4}$ and the voltage stress of $Q_{4}$ as shown in Figure 13. According to Figure 11, the inductor $L$ is charged and discharged twice during each switching period. Therefore, the equivalent switching frequency of the proposed converter is double that of the real switching frequency $f$. This feature is beneficial to improve the dynamic performance and reduce the inductor current ripple of this converter. 


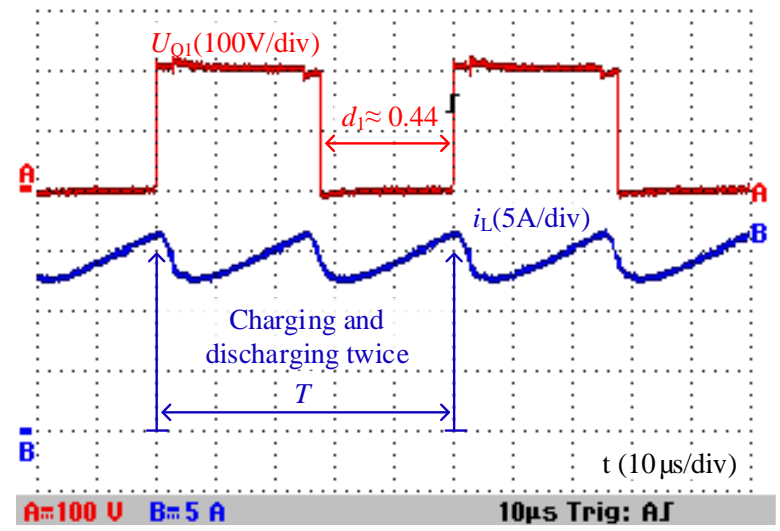

Figure 11. PWM voltage of power semiconductor $Q_{1}$ and inductor current $i_{\mathrm{L}}$.

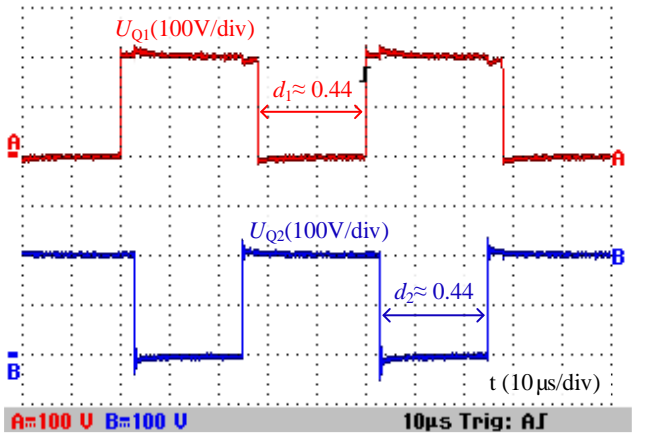

(a)

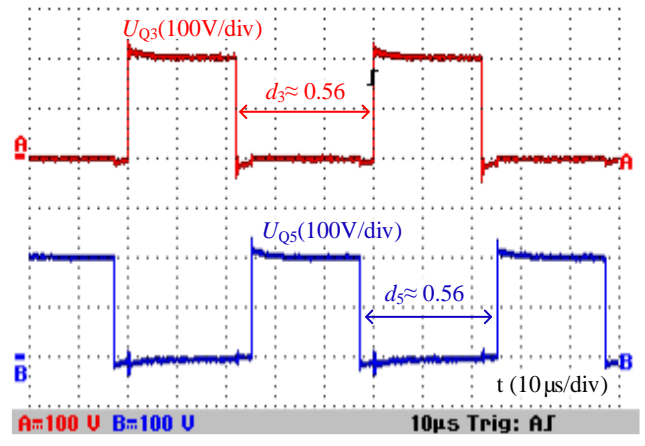

(b)

Figure 12. $\mathrm{PWM}$ voltages of power semiconductors; (a) $U_{\mathrm{Q} 1}$ and $U_{\mathrm{Q} 2} ;(\mathbf{b}) U_{\mathrm{Q} 3}$ and $U_{\mathrm{Q} 5}$.

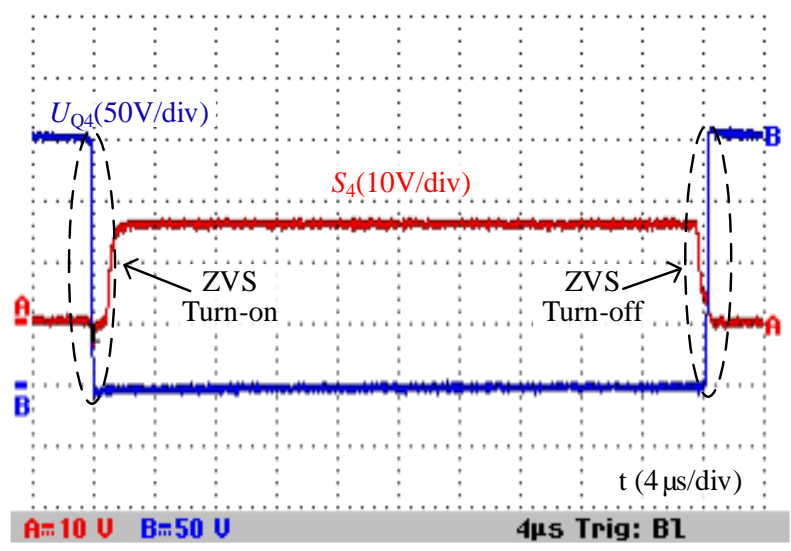

Figure 13. Voltage stress and gate signal of synchronous rectification power switch $Q_{4}$.

The voltage across clamp capacitor $C_{1}$ is approximately $200 \mathrm{~V}$, being well-consistent with $U_{\text {high }}$ as shown in Figure 14. Therefore, in the switching state 01, the clamp capacitor $C_{1}$ can maintain the forward bias of the anti-parallel diode of $Q_{5}$. The feature that all power semiconductors turn on and off only once during each switching period can be achieved. This is beneficial to avoid narrow pulses of the PWM voltage waveform at high voltage gain. 


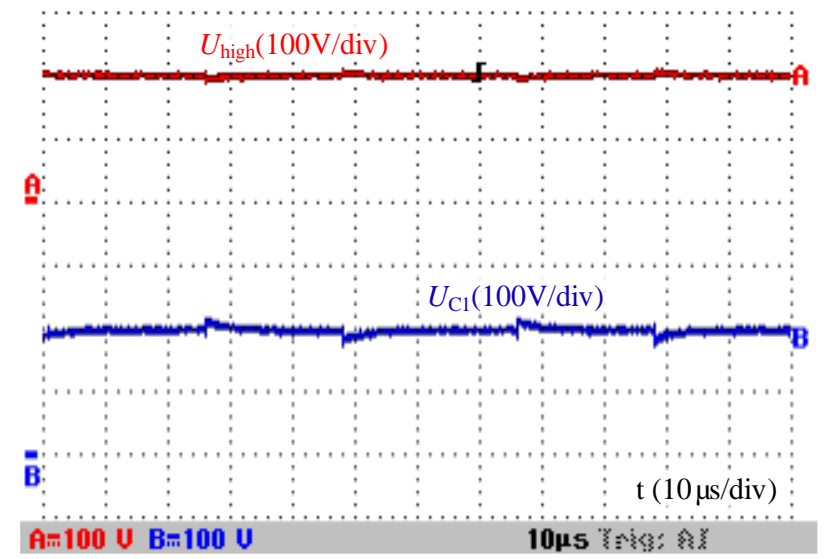

Figure 14. Output voltage and capacitor voltage stress when $U_{\text {low }}=25 \mathrm{~V}$.

In the step-up mode, $U_{\text {low }}$ and $U_{\text {high }}$ are the input and output voltage, respectively. The output voltage can stay around the reference value of $200 \mathrm{~V}$. The output/input voltage waveforms shown in Figure 15 can be obtained when changing the input voltage dynamically. According to Figure 15, when the input voltage varies continuously from $25 \mathrm{~V}$ to $60 \mathrm{~V}$, the output voltage can stay around $200 \mathrm{~V}$. The conclusion can be obtained from Figure 15 that the proposed converter can obtain a wide voltage conversion ratio from 3.3 to 8 in step-up mode.

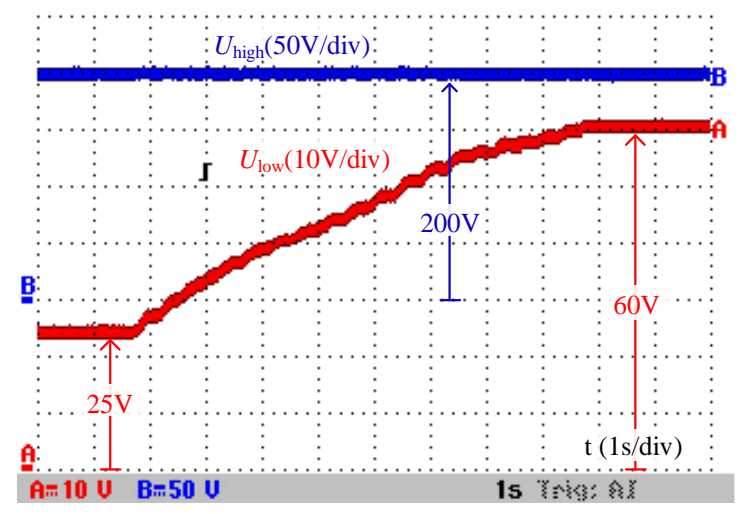

Figure 15. The output voltage and the wide-range changed input voltage from $25 \mathrm{~V}$ to $60 \mathrm{~V}$ in step-up mode.

\subsection{Experimental Results in the Step-Down Mode}

Figures 16 and 17 show the voltage waveforms of power semiconductors in the step-down operation mode. According to Figures 16 and 17, the PWM voltage of each power semiconductor is about $200 \mathrm{~V}$, approximately equaling the high-voltage side $U_{\text {high }}$. The voltage gain $M_{\text {Buck }}$ of the proposed converter is $1 / 8$ and the duty cycle $d_{\text {Buck }}$ is about 0.56 . The $O N$ state time of the power switches $Q_{3}-Q_{5}$ is about $0.56 \mathrm{~T}$ and the $O N$ state time of the power switches $Q_{1}-Q_{2}$ is about $0.44 \mathrm{~T}$. At that high voltage conversion ratio, both the $O N$ and OFF state times of those power switches are close to $0.5 \mathrm{~T}$, which is effective for avoiding the narrow pulse of the PWM voltage waveforms. In addition, the slave power semiconductors $Q_{1}$ and $Q_{2}$ also acted in the synchronous rectification operation, which turned on and turned off with ZVS, e.g., the gate signal $S_{1}$ and the voltage stress of $Q_{1}$, as shown in Figure 18. According to Figure 16, the inductor $L$ is also charged and discharged twice during each switching period. The dynamic performance of the proposed converter in step-down mode is also improved. 
According to Figure 19, the voltage across clamp capacitor $C_{1}$ is approximately $200 \mathrm{~V}$, being wellconsistent with $U_{\text {high }}$. Therefore, in the switching state 011 , the clamp capacitor $C_{1}$ can maintain the power switch $Q_{5} O N$. The feature that all power semiconductors turn on and off only once during each switching period can be achieved. This is also beneficial to avoid narrow pulses of the PWM voltage waveform at a high voltage conversion ratio, just like in step-up mode.

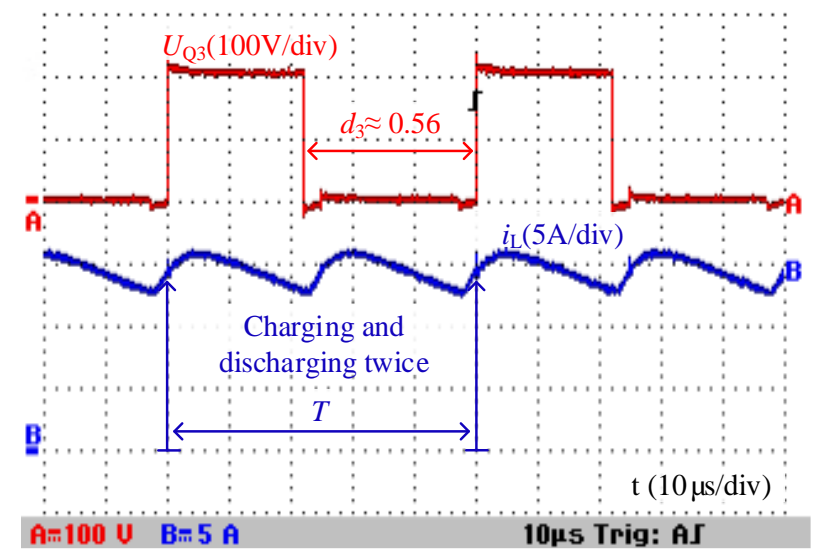

Figure 16. The PWM voltage of power semiconductor $Q_{3}$ and inductor current $i_{\mathrm{L} 1}$.

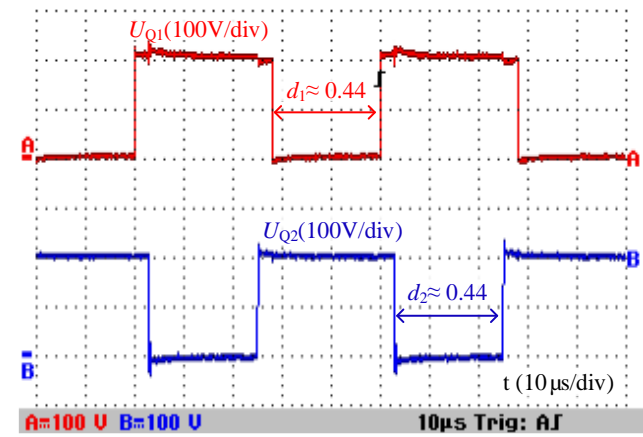

(a)

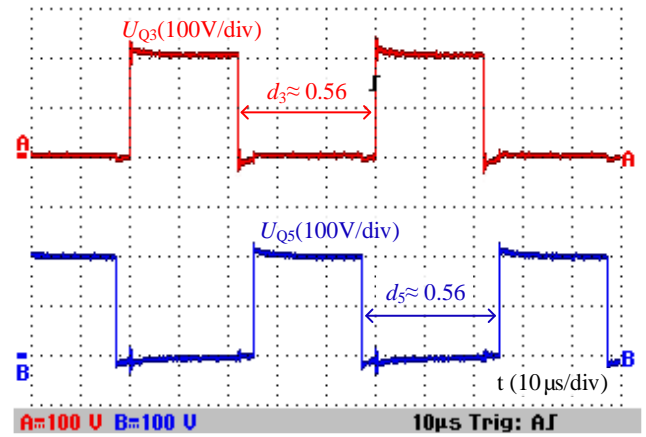

(b)

Figure 17. The PWM voltages of power semiconductors; (a) $U_{\mathrm{Q} 1}$ and $U_{\mathrm{Q} 2} ;(\mathbf{b}) U_{\mathrm{Q} 3}$ and $U_{\mathrm{Q} 5}$.

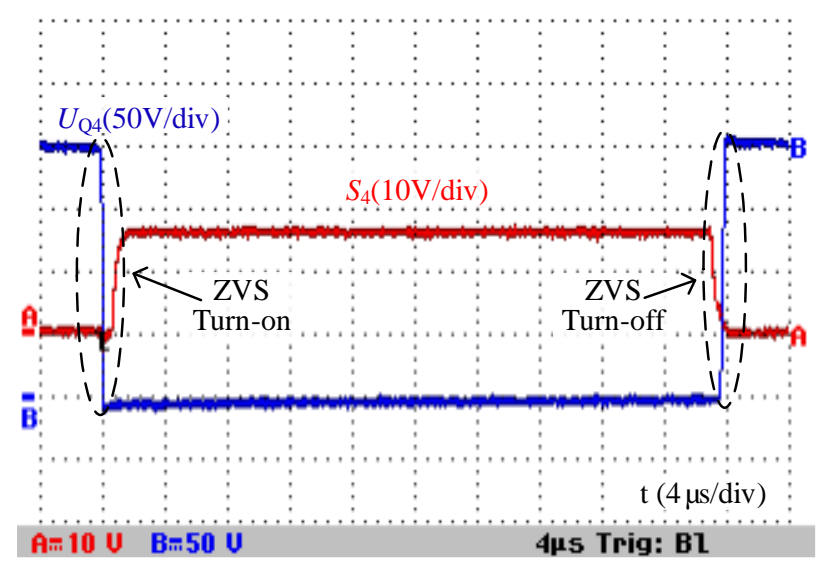

Figure 18. Gate signal and voltage stress of synchronous rectification power semiconductor $Q_{1}$. 


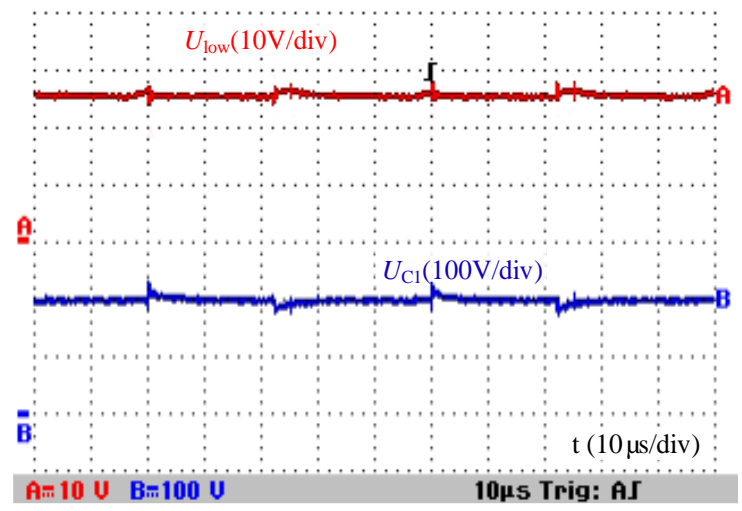

Figure 19. Output voltage and capacitor voltage stress when $U_{\text {high }}=200 \mathrm{~V}$.

In the step-down mode, the input voltage is $U_{\text {high }}$ and the output voltage is $U_{\text {low }}$. The output voltage can also stay around the reference value of $25 \mathrm{~V}$ with the action of the voltage control loop. The output/input voltage waveforms shown in Figure 20 can be obtained when changing the input voltage dynamically. According to Figure 20, when the input voltage varies continuously from $200 \mathrm{~V}$ to $75 \mathrm{~V}$, the output voltage can stay around $200 \mathrm{~V}$. The conclusion can be obtained from Figure 20 that the proposed converter can obtain a wide voltage conversion ratio from $1 / 8$ to $1 / 3$ in step-down mode.

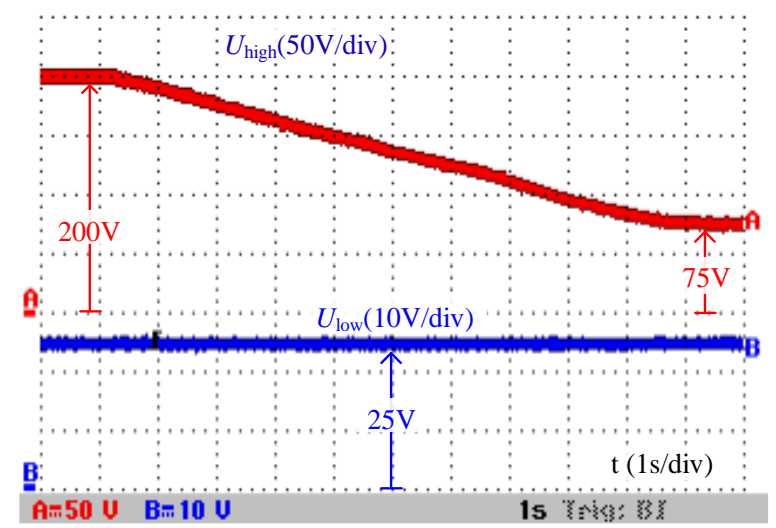

Figure 20. The output voltage and the wide-range changed input voltage from $200 \mathrm{~V}$ to $75 \mathrm{~V}$ in stepdown mode.

\subsection{Bidirectional Power Flow Experiment}

In order to verify the performance of the proposed converter in a HESS, the related experiments are carried out using the HESS shown in Figure 1. The output voltages of the SC and battery are about $42 \mathrm{~V}$ and $50 \mathrm{~V}$, respectively, and the DC load power varies with a step change between $400 \mathrm{~W}$ and $650 \mathrm{~W}$. The proposed converter is used as the power interface between the SC and the DC bus.

With the DC load being suddenly increased and decreased, changes in the output currents are shown in Figure 21, where $i_{\text {bat }}$ and $i_{\text {sc }}$ denote the output currents of the battery and the SC, respectively. When the DC load required power changes from $400 \mathrm{~W}$ to $650 \mathrm{~W}$ suddenly, the SC compensates for the required power immediately by increasing the current $i_{\mathrm{sc}}$ from 0 to $6 \mathrm{~A}$ in $20 \mathrm{~ms}$ approximately, which protects the battery by avoiding a sudden change in current and prolongs its life. Gradually, the task of supplying the power shortage is transferred from the SC to the battery. The $i_{\mathrm{sc}}$ falls to 0 from $6 \mathrm{~A}$ along with the $i_{\text {bat }}$ rising from $8 \mathrm{~A}$ to $13 \mathrm{~A}$. Similarly, when the DC load required power changes from $650 \mathrm{~W}$ to $400 \mathrm{~W}$ suddenly, the current $i_{\mathrm{sc}}$ varies from 0 to $-6 \mathrm{~A}$ in $20 \mathrm{~ms}$ approximately. As a result, the current from the battery decreases from $13 \mathrm{~A}$ to $8 \mathrm{~A}$ gradually, and the current of the SC returns to 0 from $-6 \mathrm{~A}$. When the DC load required power suddenly increases or decreases, 
the SC can respond quickly to compensate for the power gap between the battery and the DC load. In this situation, the service life of the battery is extended because of the slow changes in its output current. It can be concluded from Figure 21 that the proposed converter can cooperate well in the HESS whether the load is suddenly changed or not.

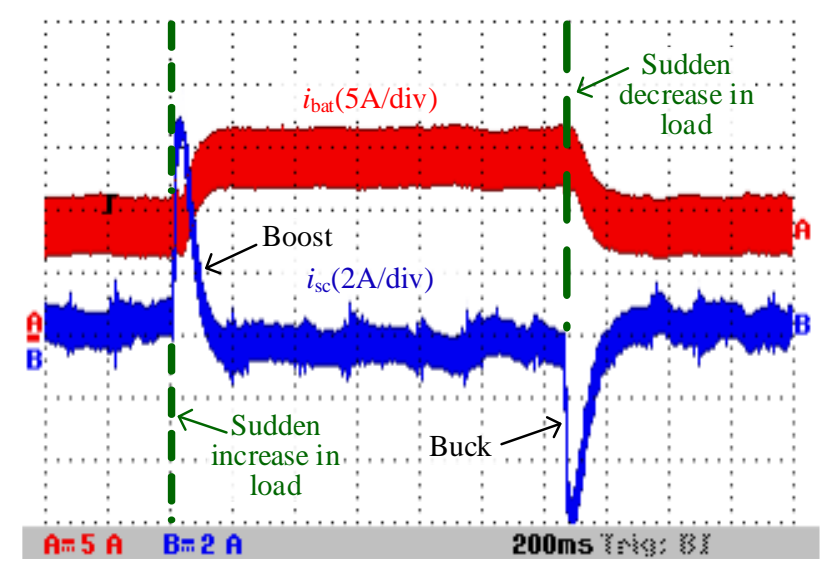

Figure 21. The output current waveforms of the battery and the super-capacitor (SC).

The efficiencies of the proposed converter in the step-up and step-down modes are shown in Figure 22. In step-up mode, $U_{\text {high }}$ is $200 \mathrm{~V}$ and $U_{\text {low }}$ varies from $25 \mathrm{~V}$ to $60 \mathrm{~V}$ continuously; in step-down mode, $U_{\text {low }}$ is $25 \mathrm{~V}$ and $U_{\text {high }}$ varies from $80 \mathrm{~V}$ to $200 \mathrm{~V}$ continuously. According to Figure 22 , the efficiency varies from $91.52 \%$ to $94.80 \%$ in step-up mode, which is slightly lower than that in the step-down mode (varies from $92.01 \%$ to $95.30 \%$ ). With the constant load power in step-up mode, the efficiency decreases accompanied by the input voltage declining due to the increasing losses caused by the growing input current. In the step-down mode, the efficiency decreases with the increase of high side voltages. Due to the increase in the high side voltages, the voltage stresses of the power semiconductors increase. Therefore, the turn on/off losses of the power semiconductors will increase.

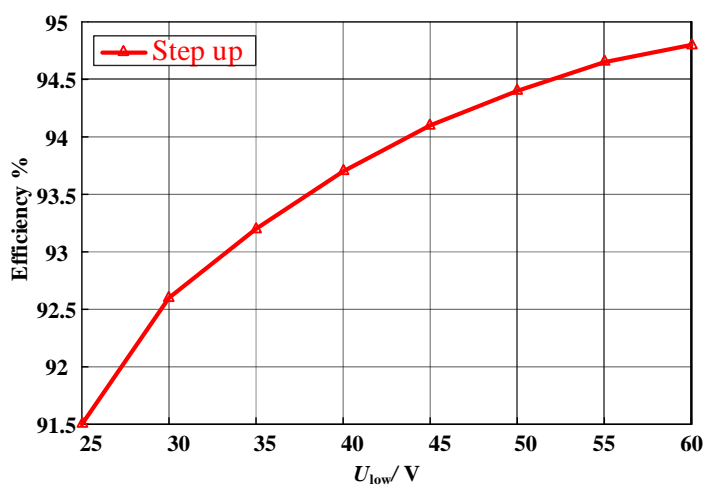

(a)

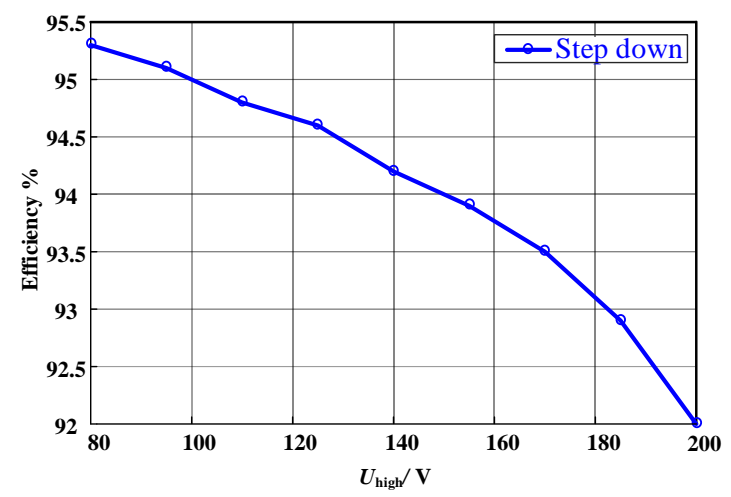

(b)

Figure 22. Efficiencies with different input voltages; (a) Step-up mode; (b) Step-down mode.

\section{Conclusions}

A new common grounded $\mathrm{H}$-type bidirectional converter was proposed in this paper. It has the advantages of a wide voltage conversion ratio and a good dynamic response in both step-down and step-up operation modes. In addition, only one inductor is used in this converter, and the inductor is charged and discharged twice during each switching period, which results in a low inductor current ripple and a small size for this converter. Due to the use of a capacitor-clamped H-type structure, 
the proposed converter can avoid the narrow pulse of the PWM voltage waveforms while achieving a high voltage conversion ratio. Besides, the efficiency of the converter is improved because the slave active power switches turn on and turn off with zero voltage. In order to prove the feasibility, the proposed converter was implemented in the laboratory with the proper voltage conversion ratio (3.3-8 in step-up mode and 1/8-1/3 in step-down mode). A theoretical analysis and experimental results proved that the proposed converter is suitable for connecting a low-voltage SC to a high-voltage DC bus.

Acknowledgments: This research was supported by the National Key R\&D Program of China (Grant: 2016YFB0900200). The authors would also like to thank the anonymous reviewers for their valuable comments and suggestions to improve the quality of the paper.

Author Contributions: Huakun Bi and Ping Wang designed the main parts of the study, including the operating principles analysis, characteristics analysis, and experiment. Zhishuang Wang helped in the hardware development, experiment, and some theoretical analysis.

Conflicts of Interest: The authors declare no conflict of interest.

\section{References}

1. Han, Y.; Chen, W.; Li, Q. Energy Management Strategy Based on Multiple Operating States fora Photovoltaic/Full Cell/Energy Storage DC Microgrid. Energies 2017, 10, 136. [CrossRef]

2. Whaite, S.; Grainger, B.; Kwasinski, A. Power quality in DC power distribution systems and microgrids. Energies 2015, 8, 4378-4399. [CrossRef]

3. Yu, X.; She, X.; Zhou, X.; Huang, A.Q. Power management for DC microgrid enabled by solid-state transformer. IEEE Trans. Smart Grid 2014, 5, 954-965. [CrossRef]

4. $\mathrm{Hu}$, J.; Cheng, K.W.E. Predictive control of power electronics converters in renewable energy systems. Energies 2017, 10, 515. [CrossRef]

5. Wang, B.; Sechilariu, M.; Locment, F. Intelligent DC microgrid with smart grid communications: Control strategy consideration and design. IEEE Trans. Smart Grid 2012, 3, 2148-2156. [CrossRef]

6. Liu, F.; Liu, J.; Zhang, H.; Xue, D. Stability issues of $Z+Z$ type cascade system in hybrid energy storage system (HESS). IEEE Trans. Power Electron. 2014, 29, 5846-5859. [CrossRef]

7. Shim, J.W.; Kim, Y.; Cho, S.-J.; Min, S.W.; Hur, K. Synergistic control of SMES and battery energy storage for enabling dispatchability of renewable energy sources. IEEE Trans. Appl. Supercond. 2013, 23. [CrossRef]

8. Xie, Q.; Wang, Y.; Kim, Y.; Pedram, M.; Chang, N. Charge allocation in hybrid electrical energy storage systems. IEEE Trans. Comput.-Aided Des. Integr. Circuits Syst. 2013, 32, 1003-1016.

9. Wang, G.; Ciobotaru, M.; Agelidis, V.G. Power smoothing of large solar PV plant using hybrid energy storage. IEEE Trans. Sustain. Energy 2014, 5, 834-842. [CrossRef]

10. Chen, X.Y.; Jin, J.X.; Xin, Y.; Shu, B.; Tang, C.L.; Zhu, Y.P.; Sun, R.M. Integrated SMES technology for modern power sys-tem and future smart grid. IEEE Trans. Appl. Supercond. 2014, 24. [CrossRef]

11. Li, J; Yang, Q. Design and test of a new droop control algorithm for a SMES/battery hybrid energy storage system. Energy 2017, 118, 1110-1122. [CrossRef]

12. Xiao, J.; Wang, P.; Setyawan, L. Hierarchical control of hybrid energy storage system in DC microgrids. IEEE Trans. Ind. Electron. 2015, 62, 4915-4924. [CrossRef]

13. Shen, J.; Khaligh, A. A supervisory energy management control strategy for a battery/ultracapacitor hybrid energy storage system. IEEE Trans. Transp. Electr. 2015, 1, 223-231. [CrossRef]

14. Li, J.; Tang, Y.; Shi, J.; Gong, K.; Liu, Y.; Ren, L.; Li, J. Design and advanced control strategies of a hybrid energy storage system for the grid integration of wind power generations. IET Renew. Power Gener. 2015, 9, 89-98.

15. Choi, M.-E.; Kim, S.-W.; Seo, S.-W. Energy management optimization in a battery/supercapacitor hybrid energy storage system. IEEE Trans. Smart Grid 2012, 3, 463-472. [CrossRef]

16. Zhang, Y.; Jiang, Z.; Yu, X. Control strategies for battery/supercapacitor hybrid energy storage systems. In Proceedings of the 2008 IEEE Energy 2030 Conference, Atlanta, GA, USA, 17-18 November 2008; pp. 1-6.

17. Inoue, S.; Akagi, H. A bidirectional dc-dc converter for an energy storage system with galvanic isolation. IEEE Trans. Power Electron. 2007, 22, 2299-2306. [CrossRef] 
18. Wu, K.; De Silva, C.W.; Dunford, W.G. Stability Analysis of Isolated Bidirectional Dual Active Full-Bridge DC-DC Converter with Triple Phase-Shift Control. IEEE Trans. Power Electron. 2012, 27, 2007-2017. [CrossRef]

19. Li, W.; Wu, H.; Yu, H.; He, X. Isolated winding-coupled bidirectional ZVS converter with PWM plus phase shift (PPS) control strategy. IEEE Trans. Power Electron. 2011, 26, 3560-3570. [CrossRef]

20. Xuewei, P.; Rathore, A.K. Novel bidirectional snubberless naturally commutated soft-switching current-fed full bridge isolated DC/DC converter for fuel cell vehicles. IEEE Trans. Ind. Electron. 2014, 61, 2307-2315. [CrossRef]

21. Wai, R.J.; Wang, W.H.; Lin, C.Y. High-performance stand-alone photovoltaic generation system. IEEE Trans. Ind. Electron. 2008, 55, 240-250. [CrossRef]

22. Wai, R.J.; Wang, W.H. Grid-connected photovoltaic generation system. IEEE Trans. Circuits Syst. I Regul. Pap. 2008, 55, 953-964.

23. Forouzesh, M.; Siwakoti, Y.P.; Gorji, S.A.; Blaabjerg, F.; Lehman, B. Step-Up DC-DC Converters: A Comprehensive Review of Voltage Boosting Techniques, Topologies, and Applications. IEEE Trans. Power Electron. 2017, 32 , 9143-9178. [CrossRef]

24. Ajami, A.; Ardi, H.; Farakhor, A. A novel high step-up DC/DC converter based on integrating coupled inductor and switched-capacitor techniques for renewable energy applications. IEEE Trans. Power Electron. 2015, 30, 4255-4263. [CrossRef]

25. Shen, H.; Zhang, B.; Qiu, D.; Zhou, L. A common grounded Z-source DC-DC converter with high voltage gain. IEEE Trans. Ind. Electron. 2016, 63, 2925-2935. [CrossRef]

26. Zhang, G.; Li, Z.; Zhang, B.; Qiu, D.; Xiao, W.; Halang, W.A. A Z-source half-bridge converter. IEEE Trans. Ind. Electron. 2014, 61, 1269-1279. [CrossRef]

27. Takiguchi, T.; Koizumi, H. Quasi-Z-source dc-dc converter with voltage-lift technique. In Proceedings of the 39th Annual Conference of the IEEE Industrial Electronics Society, IECON 2013, Vienna, Austria, 10-13 November 2013; pp. 1191-1196.

28. Tang, Y.; Wang, T.; He, Y. A switched-capacitor-based active-network converter with high voltage gain. IEEE Trans. Power Electron. 2014, 29, 2959-2968. [CrossRef]

29. Tang, Y.; Fu, D.; Wang, T.; Xu, Z. Hybrid switched-inductor converters for high step-up conversion. IEEE Trans. Ind. Electron. 2015, 62, 1480-1490. [CrossRef]

30. Tang, Y.; Wang, T.; Fu, D. Multicell switched-inductor/switched-capacitor combined active-network converters. IEEE Trans. Power Electron. 2015, 30, 2063-2072. [CrossRef]

31. Ardi, H.; Ajami, A.; Kardan, F.; Avilagh, S.N. Analysis and implementation of a no-isolated bidirectional DC-DC converter with high voltage gain. IEEE Trans. Power Electron. 2016, 63, 4878-4888. [CrossRef]

32. Zhang, Y.; Liu, Q.; Li, J.; Sumner, M. A Common Ground Switched-Quasi-Z-Source Bidirectional DC-DC Converter with Wide-Voltage-Gain Range for EVs with Hybrid Energy Sources. IEEE Trans. Ind. Electron. 2017, PP. [CrossRef]

33. Zhou, X.; Donati, M.; Amoroso, L. Improved light-load efficiency for synchronous rectifier voltage regulator module. IEEE Trans. Power Electron. 2000, 15, 826-834. [CrossRef]

34. Wang, J.; Wu, S. A Novel Control Scheme of Synchronous Buck Converter for ZVS in Light-Load Condition. IEEE Trans. Power Electron. 2011, 26, 3265-3273. [CrossRef]

35. Zhang, Y.; Li, Y. Energy Management Strategy for Supercapacitor in Droop-Controlled DC Microgrid Using Virtual Impedance. IEEE Trans. Power Electron. 2017, 32, 2704-2716. [CrossRef]

36. Xu, Q.; Hu, X.; Wang, P.; Xiao, J.; Tu, P.; Wen, C.; Lee, M.Y. A Decentralized Dynamic Power Sharing Strategy for Hybrid Energy Storage System in Autonomous DC Microgrid. IEEE Trans. Ind. Electron. 2017, 64, 5930-5941. [CrossRef]

(C) 2018 by the authors. Licensee MDPI, Basel, Switzerland. This article is an open access article distributed under the terms and conditions of the Creative Commons Attribution (CC BY) license (http:/ / creativecommons.org/licenses/by/4.0/). 